\title{
Glacial isostatic adjustment and the radial viscosity profile from inverse modeling
}

\author{
Georg Kaufmann \\ Institut für Geophysik, Universität Göttingen, Göttingen, Germany
}

Kurt Lambeck

Research School of Earth Sciences, Australian National University, Canberra, ACT, Australia

Received 8 June 2001; revised 10 March 2002; accepted 10 May 2002; published 8 November 2002.

[1] A formal inverse procedure is used to infer radial mantle viscosity profiles from several observations related to the glacial isostatic adjustment process. The data sets consist of Late Pleistocene and Holocene sea level data from Scandinavia, the Barents Sea, Central Europe, Canada, and the far field, as well as observations of changes in the Earth's rotation and gravitational field, and present-day uplift and gravity changes in Scandinavia. Inferences of mantle viscosity are robust against assumptions such as the a priori viscosity model and model discretization. However, the quality of ice sheet reconstruction remains crucial for the inverse inference. The importance to discuss regional mantle viscosity models in view of the lateral variability in mantle properties has been evident. Our inference suggests a two order of magnitude increase of mantle viscosity with depth, and volume-averaged upper and lower mantle viscosities around $7 \times 10^{20}$ and $2 \times 10^{22} \mathrm{~Pa} \mathrm{~s}$, respectively. Mantle viscosity does not need to increase sharply across the $660-\mathrm{km}$ seismic discontinuity. The viscosity profiles suggested are also able to reconcile the large-scale geoid anomaly related to mantle convection. INDEX TERMS: 1236 Geodesy and Gravity: Rheology of the lithosphere and mantle (8160); 3260 Mathematical Geophysics: Inverse theory; 1239 Geodesy and Gravity: Rotational variations; 3210 Mathematical Geophysics: Modeling; KEYWORDS: glacial isostatic adjustment, inverse modeling, radial viscosity profile

Citation: Kaufmann, G., and K. Lambeck, Glacial isostatic adjustment and the radial viscosity profile from inverse modeling, J. Geophys. Res., 107(B11), 2280, doi:10.1029/2001JB000941, 2002.

\section{Introduction}

[2] The inference of a mantle viscosity profile from observations related to the geodynamical deformation of the Earth has received much attention over the last decades. Two data sets have been proven to be of particular value for the inference of mantle viscosity: First, observations such as sequences of Late Pleistocene and Holocene coastlines, perturbations of the Earth's gravitational field and changes in the Earth's rotation. These observations are related to glacial isostatic adjustment during the ice-age cycles, and have been used to constrain both the thickness of the elastic lithosphere and the viscosity of the viscoelastic mantle. Second, perturbations of the Earth's hydrostatic equilibrium figure observed in large-scale geoid and gravity anomalies and related to mantle convection have been used to constrain mantle viscosity. Both data sets, while representing geodynamical forces on different timescales (tens to hundreds of thousands years for glacial isostatic adjustment, but tens of millions years for mantle convection), can nowadays be satisfactorily explained with a single viscosity profile.

Copyright 2002 by the American Geophysical Union. 0148-0227/02/2001JB000941\$09.00
Viscosities increase by one to two orders of magnitude from the upper to the lower mantle, and indicate that linear rheologies provide an adequate and consistent description of the Earth response over a timescale of $10^{3}$ to $10^{7}$ years.

[3] A representative example of the inference of mantle viscosity from Late Pleistocene and Holocene coastline data in northern Europe is the viscosity model derived by Lambeck et al. [1998a]. Here, average viscosities in the upper and lower mantle are $(3-5) \times 10^{20}$ and $(0.4-3) \times$ $10^{22} \mathrm{~Pa} \mathrm{~s}$, respectively. Earlier work, based on the inversion of British Isles sea level data, indicates that the depthdependence of the upper mantle viscosity may be important with values ranging from $10^{20} \mathrm{~Pa} \mathrm{~s}$ for the low-velocity zone beneath the lithosphere to $10^{21} \mathrm{~Pa}$ s for the transition zone [Lambeck et al., 1996] and a similar gradation is expected for the sub-Scandinavian mantle.

[4] Based on a revised relaxation time spectrum of the Scandinavian postglacial uplift, Wieczerkowski et al. [1999] inferred a viscosity of $5 \times 10^{20} \mathrm{~Pa}$ s for the upper mantle (down to $515 \mathrm{~km}$ depth). With more emphasis on the Hudson Bay gravity anomaly and two postglacial relaxation times from the Laurentide and Weichselian ice sheet centers, Simons and Hager [1997] deduced a viscosity profile with upper mantle viscosities of $2.6 \times 10^{21}$ (above $300 \mathrm{~km}$ ) and 
$1.4 \times 10^{20} \mathrm{~Pa} \mathrm{~s}$ (below $300 \mathrm{~km}$ ), and a lower mantle value of $1.1 \times 10^{22} \mathrm{~Pa}$ s. A representative example for model predictions of large-scale geoid anomalies from mantle flow models with imposed plate velocities can be found in the work of Čadek and Fleitout [1999]. Here, a best fitting viscosity model is derived, with upper and lower mantle viscosities of $10^{20}$ and $3.6 \times 10^{22} \mathrm{~Pa} \mathrm{~s}$, respectively.

[5] Two recent examples of a simultaneous interpretation of the large-scale geoid anomaly and glacially induced data sets are Forte and Mitrovica [1996] and Kaufmann and Lambeck [2000]. While Forte and Mitrovica [1996] used postglacial decay times from Hudson Bay and Scandinavia for their mantle viscosity inference, Kaufmann and Lambeck [2000] based their interpretation on a large set of Late Pleistocene and Holocene coastline data from Northern Europe, North America, and far-field sites, as well as supplementary information on the Earth variable rotation and gravity. However, both studies obtained similar viscosity profiles with a significant increase of viscosity with depth. Average upper and lower mantle viscosities inferred by Kaufmann and Lambeck [2000] are $(2-5) \times 10^{20}$ and $(1-3) \times 10^{22} \mathrm{~Pa} \mathrm{~s}$, respectively.

[6] We note that global models of glacial isostatic adjustment do not yet account for lateral variations in viscosity. However, evidence of lateral variations in mantle properties (seismic velocities, temperature, and hence viscosity) is observed in seismic studies [e.g., Su and Dziewonski, 1991; Li and Romanowicz, 1996; Romanowicz, 1998], and will certainly have an effect on predictions of glacial signatures such as sea level changes [e.g., Kaufmann and Wu, 1998; Kaufmann et al., 2000; Lambeck et al., 2002]. But in the absence of global models including lateral viscosity variations, we employ an alternative strategy by inferring regional solutions for the radial mantle viscosity profile. A second note of caution is warranted in view of the uncertainties of the ice sheet models. So far we are still in the process of improving our ice models through both regional and global modeling. However, both improved ice and Earth models are required, before we can better establish lateral structure in the mantle.

[7] In this paper we give improved mantle viscosity inferences through the application of a formal inverse procedure to palaeo-shorelines, present-day sea level and crustal response, and rotational data. We use a global ice model for the ice-age cycles. The nonlinear inversion of several subsets of the observational data provides improved viscosity profiles as regional solutions, that are also checked against possible effects from model parameter assumptions such as the a priori model, the model discretization, and the ice model employed. We discuss the resulting mantle viscosity profile and argue for a significant, possibly monotonic, increase of mantle viscosity with depth.

\section{Theory}

[8] In the next two sections, we briefly review the mathematical concepts used for the forward and inverse modeling.

\subsection{Sea Level Equation}

[9] We define Green's functions for the solid surface, $\Gamma_{R}^{L}$ and $\Gamma_{R}^{T}$, and for the geoidal surface, $\Gamma_{\Phi}^{L}$ and $\Gamma_{\Phi}^{T}$ [e.g., Farrell and Clark, 1976; Nakada and Lambeck, 1987; Mitrovica and Peltier, 1989; Han and Wahr, 1995], given by

$$
\begin{gathered}
\Gamma_{R}^{L}(\gamma, t)=\frac{a}{m_{e}} \sum_{l=0}^{\infty} h_{l}^{L}(t) P_{l}(\cos \gamma), \\
\Gamma_{R}^{T}(t)=\frac{1}{g} \sum_{l=0}^{\infty} h_{l}^{T}(t) P_{l}(\cos \gamma), \\
\Gamma_{\Phi}^{L}(\gamma, t)=\frac{a g}{m_{e}} \sum_{l=0}^{\infty}\left[\delta(t)+k_{l}^{L}(t)\right] P_{l}(\cos \gamma), \\
\Gamma_{\Phi}^{T}(t)=\sum_{l=0}^{\infty}\left[\delta(t)+k_{l}^{T}(t)\right] P_{l}(\cos \gamma) .
\end{gathered}
$$

In (1)-(4), $m_{e}$ is the Earth's mass, and $a$ the Earth's radius, $g$ the surface value of gravitational acceleration, $t$ is time, $\gamma$ is the great circle distance from the impulsive load point to the observation point, and $\delta(t)$ the Dirac function. The surface Love numbers $h^{L}$ and $k^{L}$ and the tidal Love numbers $h^{T}$ and $k^{T}$ contain the information about the viscoelastic properties of the Earth model [Love, 1911]. Here, the elastic properties are prescribed from PREM [Dziewonski and Anderson, 1981], and discretized into 200 layers. Within each layer, the elastic properties vary linearly. Viscosity is taken as a free parameter. Love numbers are then calculated with a Runge-Kutta procedure, using a pure collocation method as described by Mitrovica and Peltier [1992].

[10] From the Green's functions (1)-(4), we derive the response functions for perturbations of the Earth solid $(R)$ and geoidal $(G)$ surfaces as sums of both surface and rotation-induced load forcing [e.g., Milne and Mitrovica, 1998], which read:

$$
\begin{aligned}
R(\theta, \varphi, t)= & R^{L}(\theta, \varphi, t)+R^{T}(\theta, \varphi, t) \\
R^{L}(\theta, \varphi, t)= & \int_{-\infty}^{t} \int_{0}^{2 \pi} \int_{0}^{\pi} a^{2} L\left(\theta^{\prime}, \varphi^{\prime}, t^{\prime}\right) \Gamma_{R}^{L}\left(\gamma, t-t^{\prime}\right) \\
& \cdot d \varphi^{\prime} \sin \theta^{\prime} d \theta^{\prime} d t^{\prime} \\
R^{T}(\theta, \varphi, t)= & \int_{-\infty}^{t} \int_{0}^{2 \pi} \int_{0}^{\pi} \Lambda\left(\theta^{\prime}, \varphi^{\prime}, t^{\prime}\right) \Gamma_{R}^{T}\left(t-t^{\prime}\right) \\
& \cdot d \varphi^{\prime} \sin \theta^{\prime} d \theta^{\prime} d t^{\prime}
\end{aligned}
$$

$$
G(\theta, \varphi, t)=G^{L}(\theta, \varphi, t)+G^{T}(\theta, \varphi, t)+\frac{\Delta \Phi(t)}{g},
$$$$
G^{L}(\theta, \varphi, t)=\frac{1}{g} \int_{-\infty}^{t} \int_{0}^{2 \pi} \int_{0}^{\pi} a^{2} L\left(\theta^{\prime}, \varphi^{\prime}, t^{\prime}\right) \Gamma_{\Phi}^{L}\left(\gamma, t-t^{\prime}\right)
$$

$$
\cdot d \varphi^{\prime} \sin \theta^{\prime} d \theta^{\prime} d t^{\prime}
$$

$$
\begin{aligned}
G^{T}(\theta, \varphi, t)= & \frac{1}{g} \int_{-\infty}^{t} \int_{0}^{2 \pi} \int_{0}^{\pi} \Lambda\left(\theta^{\prime}, \varphi^{\prime}, t^{\prime}\right) \Gamma_{\Phi}^{T}\left(t-t^{\prime}\right) \\
& \cdot d \varphi^{\prime} \sin \theta^{\prime} d \theta^{\prime} d t^{\prime}
\end{aligned}
$$

Here, $\theta$ and $\varphi$ are colatitude and east longitude, respectively, and $L(\theta, \varphi, t)$ and $\Lambda(\theta, \varphi, t)$ are the surface and the rotation- 
induced load functions. The third term on the RHS of $G$ in (6) is a time-dependent shift of the entire equipotential surface to ensure conservation of mass.

[11] The surface load comprises three contributions: The Late Pleistocene ice sheet distribution, $I(\theta, \phi, t)$, the recent mass imbalance from the Antarctic and Greenland ice sheets and probably contributions from small mountain glaciers, $M(\theta, \phi, t)$, and the corresponding ocean load, $W(\theta, \phi, t)$. Introducing the densities of ice and water, $\rho_{I}$ and $\rho_{W}$, we find:

$$
L(\theta, \phi, t)=\rho_{I} I(\theta, \phi, t)+\rho_{I} M(\theta, \phi, t)+\rho_{W} W(\theta, \phi, t) .
$$

The rotation-induced load, which is the contribution from the glacially induced change in the Earth's rotation, correct to first order, is given by [e.g., Milne and Mitrovica, 1998]

$$
\Lambda(\theta, \phi, t)=\Lambda_{00}(t) Y_{00}(\theta, \phi)+\sum_{m=-1}^{+1} \Lambda_{2 m}(t) Y_{2 m}(\theta, \phi),
$$

where the coefficients are given by

$$
\begin{aligned}
& \Lambda_{00}(t)=\frac{2 \omega^{2} a^{2}}{3} m_{3}(t) \\
& \Lambda_{20}(t)=-\frac{4 \omega^{2} a^{2}}{6 \sqrt{5}} m_{3}(t) \\
& \Lambda_{21}(t)=-\frac{\omega^{2} a^{2}}{\sqrt{15}}\left[m_{1}(t)+i m_{2}(t)\right] .
\end{aligned}
$$

In (9), $\omega$ is the mean angular velocity of the Earth, and the $\Lambda_{21}$-term provides the dominant contribution. The position of the rotation axis with respect to the Earth's crust, $\mathbf{m}(t)=$ $m_{1}(t)+i m_{2}(t)$, and the rotational velocity, $\dot{m}_{3}(t)$, can be derived by solving the Euler equations for a rotating Earth. Johnston and Lambeck [1999] found:

$$
\begin{gathered}
m_{1}(t)+i m_{2}(t)=-\frac{4 \pi a^{4}}{\sqrt{15}(C-A)}\left(1-\frac{k_{2}^{T}(t)}{k_{2}^{T f}}\right)^{-1}\left[1+k_{2}^{L}(t)\right] * L_{21}(t), \\
\cdot m_{3}(t)=\frac{2 \sqrt{5} m_{e} a^{2}}{3 C} C_{20}(t),
\end{gathered}
$$

with $A$ and $C$ the equatorial and polar moments of inertia, and $k_{2}^{T f}$ the fluid limit of the tidal Love number of the gravitational potential, $k_{2}^{T}(t)$. The complex degree two, order one coefficient of the surface load is denoted by $L_{21}(t)$.

[12] With the surface and rotation-induced loads defined and an Earth model described in terms of Love numbers, we solve the sea level equation [Farrell and Clark, 1976] given by

$$
W(\theta, \varphi, t)=C(\theta, \varphi, t)[G(\theta, \varphi, t)-R(\theta, \varphi, t)] .
$$

In (11), $C(\theta, \varphi, t)$ is the time-dependent ocean function [Munk and MacDonald, 1960], equaling one over oceanic areas and zero elsewhere. As $W$ appears on both sides in (11), the sea level equation is an integral equation, which we solve iteratively, using the pseudo-spectral approach
[Mitrovica et al., 1994; Milne and Mitrovica, 1998]. Once we have determined the ocean load $W$, we derive several quantities of interest, such as relative sea level change, present-day surface motions, time-dependent perturbations of the gravitational field, and rotational contributions from the ice-ocean imbalance. These calculated quantities are then compared to observational data.

\subsection{Inverse Inferences}

[13] We use a formal inverse procedure to infer the radial viscosity profile. We solve a damped, weighted, nonlinear inverse problem [e.g., Tarantola and Valette, 1982; Mitrovica and Peltier, 1991] for the viscosity profile. The quantity minimized is the sum of the least squares misfit $\chi^{2}$ and the weighted length $D$ of the model vector $a_{i}$,

$$
\begin{aligned}
& \chi^{2}\left(a_{k}\right)=\left[o_{i}-p_{i}\right]\left[C o_{i j}^{d}\right]^{-1}\left[o_{j}-p_{j}\right], \\
& D\left(a_{k}\right)=\left[a_{i}-a_{i}^{0}\right]\left[C o_{i j}^{m}\right]^{-1}\left[a_{j}-a_{j}^{0}\right] .
\end{aligned}
$$

In (12), the $o_{i}$ and $p_{i}$ are observed and predicted data $(i=1$, $n)$, respectively. The vector $a_{i}$ is the model parameter space defined here by 11 depth intervals of the logarithm of the viscosity and the lithospheric thickness, and $a_{i}^{0}$ is its a priori value. The matrices $C o_{i j}^{d}$ and $C o_{i j}^{m}$ are the data and model covariance matrices,

$$
\begin{aligned}
& C o_{i j}^{d}=2 \Delta o_{i}^{2} \delta_{i j}, i, j=1, n, \\
& C o_{i j}^{m}=2 \Delta a_{i}^{2}\left\{\begin{aligned}
1, & i=j \\
\exp \left[-\frac{\Delta h^{2}}{2 c^{2}}\right], & i \neq j
\end{aligned}\right\} i, j=1, m,
\end{aligned}
$$

with $\Delta o_{i}$ the observational uncertainty of the data, $\delta_{i j}$ the Kronecker delta, $\Delta a_{i}$ the uncertainty of the logarithm of the viscosity $(0.05)$ or of lithospheric thickness $(10 \mathrm{~km}), \Delta h=$ $h_{i}-h_{j}$ the distance between the $i$-th and $j$-th layer, and $c$ the correlation length, fixed to $400 \mathrm{~km}$ in most cases. For $c>0$ $\mathrm{km}$, neighboring viscosity bins are influencing each other, while for $c=0 \mathrm{~km}$ each viscosity bin is inferred independently from its neighbors. Hence, choosing the correlation length above zero smoothes the viscosity profile and avoids large viscosity contrasts between neighboring layers. The values for $\Delta a_{i}$ and $c$ have been chosen to optimize the inversion results in terms of the least squares misfit, $\chi^{2}$.

[14] Following Tarantola and Valette [1982], we minimize $\chi^{2}+D$ by differentiating this sum with respect to $a_{i}$ and setting it to zero. As our model is nonlinear, $o_{i}=$ $p_{i}\left(a_{j}\right)$, we apply an iterative approach to infer the best fitting model parameter vector. This implies calculating the Frechet kernel matrix $J_{i j}=\partial p_{i} / \partial a_{j}$. For a given a priori model parameter vector $a_{i}^{0}$, we can then improve the solution iteratively for the $k+1$-th step as

$$
\begin{aligned}
\mathbf{a}_{\mathbf{k}+\mathbf{1}}= & \mathbf{a}_{0}+\left\{\mathbf{J}_{\mathbf{k}}^{T}\left[\mathbf{C o} \mathbf{o}^{\mathbf{d}}\right]^{-1} \mathbf{J}_{\mathbf{k}}+\left[\mathbf{C o}{ }^{\mathbf{m}}\right]^{-1}\right\}^{-1} \\
& \cdot \mathbf{J}_{\mathbf{k}}{ }^{T}\left[\mathbf{C o}{ }^{\mathbf{d}}\right]^{-1}\left[\mathbf{o}-\mathbf{p}_{\mathbf{k}}+\mathbf{J}_{\mathbf{k}}\left(\mathbf{a}_{\mathbf{k}}-\mathbf{a}_{0}\right)\right] .
\end{aligned}
$$

Here, bold field quantities are used as short-term notations for vector and matrix fields: $\mathbf{J}=\left[J_{i j}\right], \mathbf{C o}^{\mathbf{d}}=\left[C o_{i j}^{d}\right], \mathbf{C o}^{\mathbf{m}}=$ $\left[C o_{i j}^{m}\right], \mathbf{o}=\left[o_{i}\right]$, and $\mathbf{p}=\left[p_{i}\right]$. The a posteriori model 


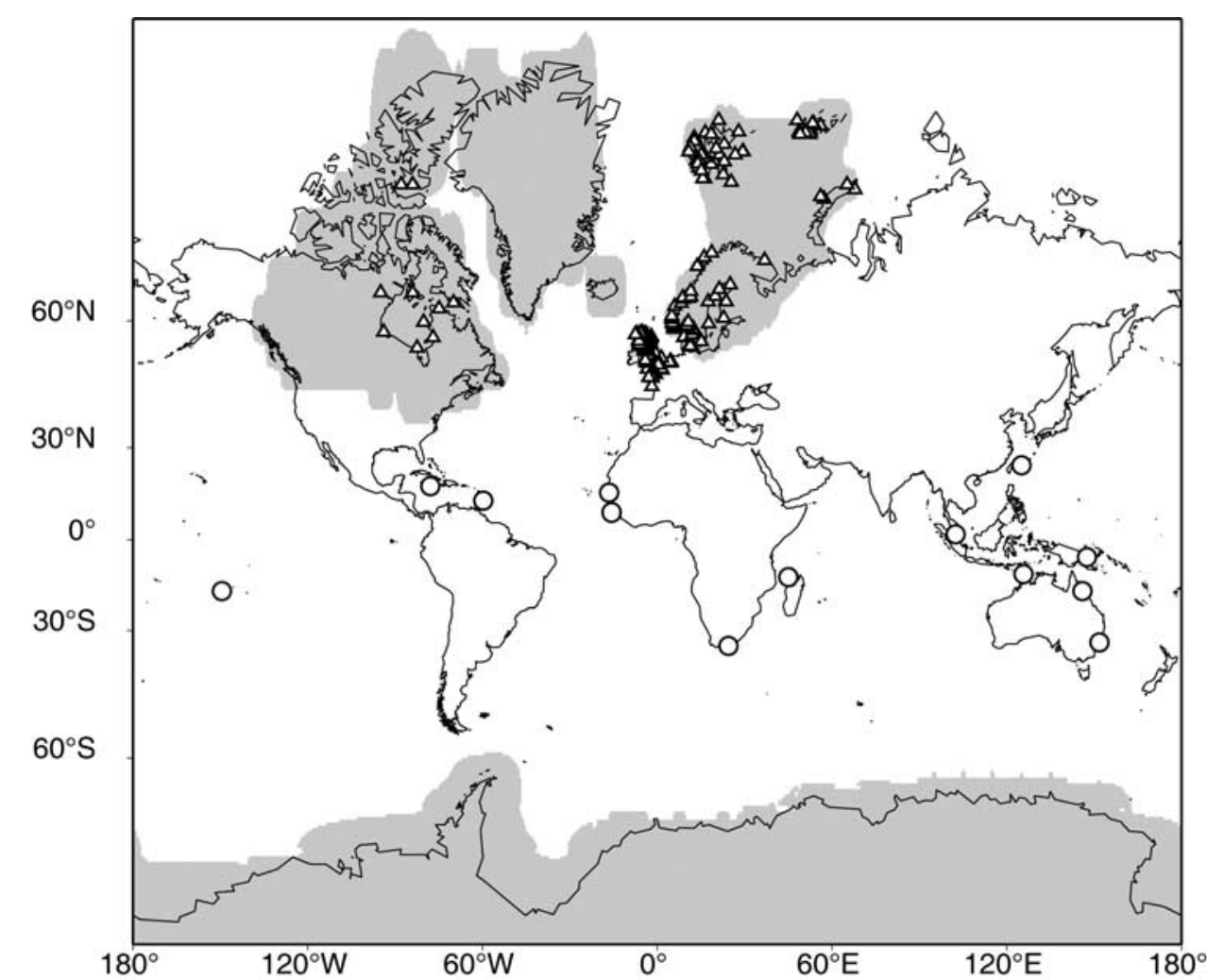

Figure 1. Ice margins at the last glacial maximum (grey) for the model described in the text. The triangles denote localities of near-field observed sea-level indicators, the circles denote far-field localities. Note that each locality comprises one or more observed sea-level indicators.

covariance matrix can be used to assess the reliability of the inverse inference. It reads:

$$
\left.\mathbf{C o}_{\text {post }, k}^{m}=\left\{\mathbf{J}_{\mathbf{k}}^{T}[\mathbf{C o}]^{\mathbf{d}}\right]^{-1} \mathbf{J}_{\mathbf{k}}+\left[\mathbf{C o}^{\mathbf{m}}\right]^{-1}\right\}^{-1}
$$

Note that (15) is only meaningful, if predictions are weakly nonlinear with respect to $a_{i}$ [e.g., Mitrovica and Peltier, 1991; Snieder, 1998]. We achieve this by inferring the logarithm of the viscosity in 11 layers in the mantle. We use the ratio of the a posteriori to the a priori variances (normalized posterior variances) on the main diagonal of (15) as a measure of the resolving power of the data within a given depth. For values below unity, this normalized posterior variances indicate an improvement in fitting the posterior model to the data with respect to the a priori model. The inverse procedure (14) for our problem usually converges within four to six iterations.

\section{Ice-Ocean Mass Transfer Models}

[15] We calculate the Late Pleistocene and contemporary ice-ocean mass transfer by solving the sea level equation on a rotating Earth. We follow the pseudo-spectral approach outlined by Mitrovica et al., [1994] and Mitrovica and Milne [1998]. For the Late Pleistocene glacial history, the ice model RSES is used. RSES is a global ice model comprising Late Pleistocene ice sheets over North America, North Europe, Greenland, the British Isles, and Antarctica. The extent and the melting history follow model ICE-1 [Peltier and Andrews, 1976] for the Laurentide Ice Sheet and Greenland, model FBKS8 [Lambeck et al., 1998a] for the Fennoscandian and Barents Sea Ice Sheets, model BK4 [Lambeck, 1993] for the British Ice Sheet, and model ANT3 [Nakada and Lambeck, 1988] for the Antarctic Ice Sheet. All reconstructions are based on glaciological and geomorphological evidence and thus reflect the approximate extent of the Late Pleistocene Ice Sheets throughout the last glacial cycle. Of these ice sheets only the Fennoscandian, Barents Sea and British Isles ice sheets are high spatial and temporal resolution models that are consistent with the majority of the field evidence for ice-margin retreat and with the rebound data. The Antarctic and Laurentide ice sheets are both of a coarse resolution and are less suitable for high-resolution rebound modeling for areas within and close to their former margins. For this reason we use North American rebound data only from sites near the center of rebound. The ice volume at last glacial maximum approximately 22,000 years BP corresponds to $127 \mathrm{~m}$ of eustatic sea level change, and the maximum extent is shown in Figure 1. We simulate the time-dependence of the ice sheets throughout the Late Pleistocene glacial cycles by modeling the last two cycles with linear functions approximating the oxygen isotope data record [Chappell and Shackleton, 1986] and by assuming an average ice load before that time. This parameterization of the last glacial cycles has been shown to be sufficient to correctly predict changes in the Earth's gravitational field and rotation [Johnston and Lambeck, 1999].

[16] In addition to the Late Pleistocene melting we include the J92, S1, and S2M scenarios for the recent mass 
imbalance of the Antarctic Ice Sheet [James and Ivins, 1997] to account for the effects of present-day melting on signatures such as changes in $C_{20}$ and true polar wander. The J92 model accounts for $0.44 \mathrm{~mm} \mathrm{yr}^{-1}$ of global present-day sea level rise, mainly as a result of mass changes in West Antarctica. This scenario provides only half to one third of the observed present-day sea level rise of around $(1.5 \pm 0.5) \mathrm{mm} \mathrm{yr}^{-1}$ [e.g., Gornitz et al., 1982; Lambeck et al., 1998b; Church et al., 2001]. The actual contribution from Antarctic melting to global sea level rise is likely to be considerably less, and even negative [Church et al., 2001], as modeled in the S1 and S2M scenarios. We use the J92 scenario here as an indicative model of the potential significance of present-day ice sheet imbalance on the glacial isostatic adjustment parameter estimation. In our models, present-day melting has contributed to contemporary sea level rise for the last 100 years.

\section{Observations}

[17] Perturbations of the Earth' shape caused by the glacial mass redistributions are recorded in successions of Late Pleistocene and Holocene coastlines that are found both below and above the present sea level. The global distribution of these indicators of relative sea level change (RSL) reveals the complex response of the glacial isostatic adjustment process and are widely used to constrain the radial viscosity profile. For our analysis, we have chosen observed sea level indicators from Scandinavia (569), the Barents Sea (264), NW Europe (487), and Canada (58), sampling the near field of the northern hemisphere part of the Late Pleistocene Ice Sheet fairly evenly (Figure 1). Wile the RSL data for the European region reflect the complicated three-dimensional response of the Earth well and thus are reliable constraints for mantle viscosity models, the chosen Canadian RSL data are a preliminary database with much coarser resolution, which needs to be improved in the future. The glacial response in the far field of the former Late Pleistocene ice sheets is monitored by 310 RSL sites located around the globe. The remaining departure from isostatic equilibrium at present is well documented over Fennoscandia, where lake level and tide gauge data from mareographs have been used to reconstruct a map of present radial uplift velocities [Ekman, 1998]. Inferences of ice- and Earth-model parameters from these data are consistent with results inferred from the geological record [Lambeck et al., 1998a, 1998b]. The uplift map based on the mareograph data has recently been reproduced by the BIFROST campaign [Scherneck et al., 1998, 2001], which used repeated GPS measurements over a station network encompassing the entire Fennoscandian Peninsula.

[18] Currently, the position of the rotation pole slowly drifts along the $70^{\circ} \mathrm{W}$ meridional plane with a rate of $10^{-6}{ }^{\circ} \mathrm{yr}^{-1}$ [Lambeck, 1980]. The secular drift is directed toward the center of the former Laurentide Ice Sheet. Superimposed on the secular drift, which has been monitored for the last 100 years, are other decade-long oscillations. The observed rotational velocity of the Earth has a secular component, resulting in an increase of the length of the day. Again decadal and longer oscillations are superimposed onto the secular term. In addition to the geological observations mainly sensitive to viscosity variations within the upper 1000-1400 km of the Earth's mantle [e.g., Mitrovica, 1996], we use the observed rate of change of the spherical harmonic degree-two component of the Earth's gravitational field, $\dot{C}_{20}=(3.93 \pm 0.35) \times 10^{-19} \mathrm{~s}^{-1}[$ Nerem and Klosko, 1996], and the observed true polar wander velocity, $T P W=(3.33 \pm 0.08)$ marcsec $\mathrm{yr}^{-1}[$ McCarthy and Luzum, 1996] to complement the predictions of glacial isostatic adjustment. The latter two observables have sensitivities for the radial viscosity profile peaking in the lower mantle [Mitrovica and Peltier, 1991; Peltier, 1998b; Mitrovica and Milne, 1998; Johnston and Lambeck, 1999].

\section{Results}

[19] The results presented in this section are based on model predictions on a spherically symmetric, compressible, Maxwell-viscoelastic Earth model. The elastic structure is derived from PREM [Dziewonski and Anderson, 1981], and the a priori thickness of the elastic lithosphere is fixed to $80 \mathrm{~km}$, in accordance with inferences from Lambeck et al. [1996, 1998a]. Mantle viscosity is parameterized in eleven layers with constant viscosity within each layer. The Earth's core is assumed to be inviscid, and incorporated as lower boundary condition. As outlined in section 2.1, we solve the sea level equation on a rotating Earth with an iterative procedure in the spectral domain, the spherical harmonic expansion is truncated at degree 192.

\subsection{Dependence on Model Parameters}

[20] We start with a discussion of results from the formal inverse procedure introduced in section 2.2 for different model assumptions. Our aim for this section is to infer the dependencies of the final solution on model assumptions such as the a priori model vector and model parameter such as correlation length and ice model.

\subsubsection{A Priori Viscosity Model}

[21] In a first set of models, we discuss effects resulting from different a priori model vectors. The observational data used are the Scandinavian sea level data, $\dot{C}_{20}$, and TPW. In Figure $2 \mathrm{a}$, the a priori model used is based on the forward results from Lambeck et al. [1998a], with an $80 \mathrm{~km}$ thick elastic lithosphere of infinite viscosity, and upper and lower mantle viscosities of $5.1 \times 10^{20}$ and $1.1 \times 10^{22} \mathrm{~Pa} \mathrm{~s}$, respectively. We observe a significant reduction in the least squares misfit from an a priori value of $\chi_{p r}^{2}=4.34$ to an a posteriori value of $\chi_{p o}^{2}=2.63$, with a reduction around $40 \%$. The a posteriori viscosity profile exhibits a large deviation from its a priori values. Viscosities in the upper mantle are increasing from around $4 \times 10^{20}$ to $2 \times 10^{21} \mathrm{~Pa} \mathrm{~s}$. The large jump in viscosity between the upper and lower mantle is maintained in the a posteriori profile, and viscosities in the lower mantle increase from $6 \times 10^{22} \mathrm{~Pa}$ s below the $660-\mathrm{km}$ seismic discontinuity (660) to around $9 \times 10^{22} \mathrm{~Pa}$ s in 1000 $\mathrm{km}$ depth. Below that depth, viscosity is monotonically decreasing to values around $10^{22} \mathrm{~Pa} \mathrm{~s}$ at the core-mantle boundary $(\mathrm{CMB})$. The normalized posterior variances have dropped by more than $50 \%$ in the mantle down to $1500 \mathrm{~km}$ depth, and are still significantly reduced below that depth. Only in its lowermost part close to the CMB is the reduction less good. The lithospheric thickness has increased to $100 \mathrm{~km}$, which might be a consequence of the stiffer lower mantle (a trade-off exists between lithospheric thickness and 

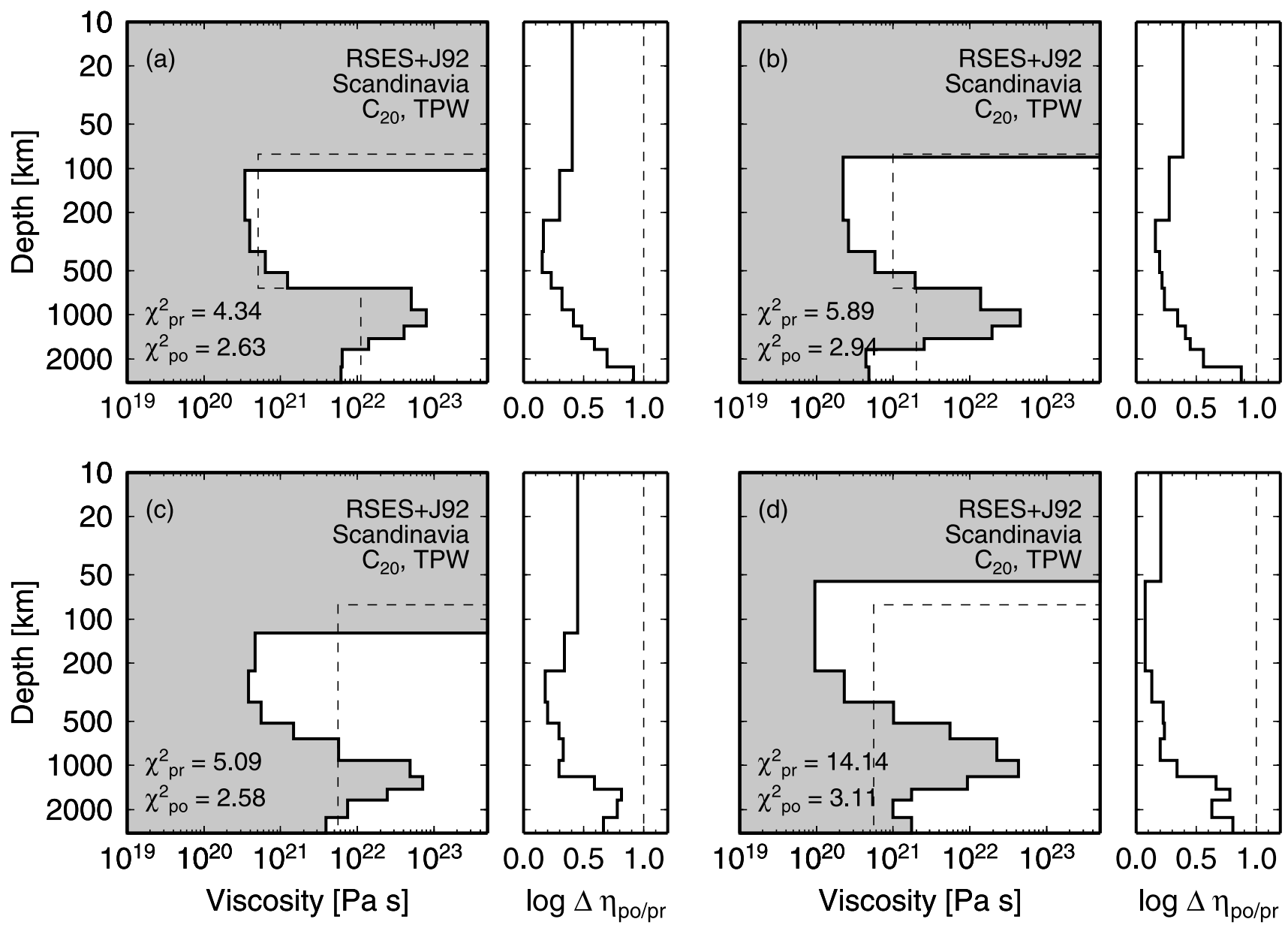

Figure 2. Four posterior viscosity models (thick lines) derived from different a priori viscosity profiles (dashed lines). The data used are the Scandinavian sea-level data, $\dot{C}_{20}$, and $T P W$. The smaller panels show the normalized posterior variances (solid lines).

viscosity) [see also Lambeck, 1993; Lambeck and Chappell, 2001].

[22] In Figure $2 b$, the a priori viscosity model comprises an $80 \mathrm{~km}$ thick elastic lithosphere of infinite viscosity, and upper and lower mantle viscosities of $1 \times 10^{21}$ and $2 \times 10^{21}$ Pa s, respectively. This model has been favored by Tushingham and Peltier [1991] on the basis of the ICE-3G global deglaciation model and relative sea level data from the near field. The least squares misfit has improved from $\chi_{p r}^{2}=5.89$ to $\chi_{p o}^{2}=2.94$, a reduction of more than $50 \%$. The a posteriori viscosity model is similar to the previous inference, with viscosity increasing throughout the upper mantle to a maximum in the central parts of the lower mantle, then decreasing again. However, the large jump of viscosity across the 660-discontinuity is replaced by a more moderate variation. Hence it is clear that the viscosity jump across the transition zone may be an artifact of the a priori model, which does not need to be a realistic feature. Lithospheric thickness, again a free parameter, has remained around $80 \mathrm{~km}$.

[23] In Figures $2 \mathrm{c}$ and $2 \mathrm{~d}$, two uniform a priori viscosity models have been used, with viscosities of $5 \times 10^{21} \mathrm{~Pa} \mathrm{~s}$, and $5 \times 10^{20} \mathrm{~Pa} \mathrm{~s}$, respectively. While the latter a priori model cannot reduce the least squares misfit as effectively as the previous two models, the former a priori model yields $\chi_{p o}^{2}=2.58$, a $50 \%$ reduction. The a posteriori viscosity profile of Figure 2c is again similar to the first two inferences. From the results discussed above, we conclude that the dependence of the formal inverse procedure on the a priori viscosity model can be significant, and therefore several different scenarios need to be discussed to ensure the reliability of the inversion result.

\subsubsection{Correlation Length}

[24] We next illustrate the effect of the correlation length $c$ in the model covariance matrix (13). For $c=0$, the inversion within each mantle layer is independent from the neighboring layers. As it can be seen in Figure 3a, the least squares misfit improves from an a priori value of $\chi_{p r}^{2}=4.34$ to an a posteriori value of $\chi_{p o}^{2}=2.61$, which is similar to the one of the model with $c=400 \mathrm{~km}$ shown in Figure 2a. The resulting a posteriori viscosity profile has some similarities to its counterpart in Figure 2a, except a decrease in viscosity in the uppermost mantle. Here, the stiff elastic lithosphere is forcing a gradual decrease in viscosity. In the lower part of the upper mantle, viscosity is generally lower than for the model shown in Figure 2a. We note, however, that the normalized posterior variances are still large, especially in the lithosphere and the lower mantle.

\subsubsection{Discretization}

[25] We have reduced the number of layers in the mantle from ten to five to address the effect of discretization on 

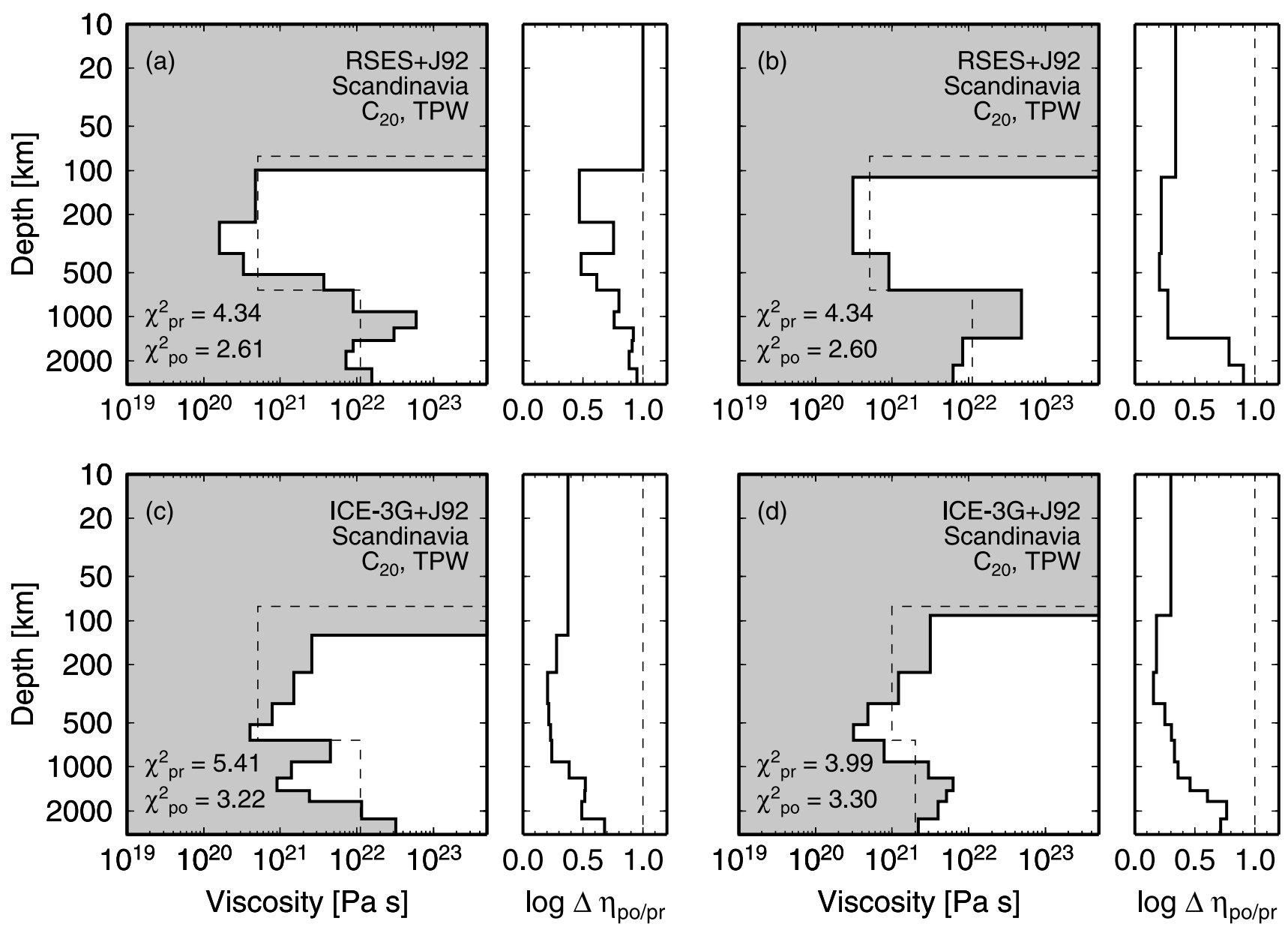

Figure 3. Four posterior viscosity models (thick lines) derived for different model parameter and a priori viscosity profiles (dashed lines). The data used are the Scandinavian sea-level data, $\dot{C}_{20}$, and $T P W$, and (a) $c=0 \mathrm{~km}$, (b) 5 mantle layers, (c) ice model ICE-3G and Lambeck et al. [1998a] a priori viscosity model, (c) ice model ICE-3G and Tushingham and Peltier [1991] a priori viscosity model. The smaller panels show the normalized posterior variances (solid lines).

the inferred viscosity profile. However, the resulting a posteriori profile shown in Figure $3 b$, though coarser than the profile in Figure 2a, reveals the same depth-dependence, as do the normalized posterior variances. The least squares misfit is also reduced to similar values (2.60). Hence, the uncertainties of the observed data limit the apparent resolving power of the inversion in terms of the mantle viscosity profile.

\subsubsection{Ice Model}

[26] In the last two inversions shown in Figure 2, we have replaced the ice model RSES by the ice model ICE3G from Tushingham and Peltier [1991]. While ice model RSES is mainly based on geomorphological and glaciological field evidence, ICE-3G has been constructed by fitting RSL data from the near field. Hence, it is biased by the Earth model used for the reconstruction, which is characterized by an upper mantle viscosity of $10^{21} \mathrm{~Pa} \mathrm{~s}$, and a lower mantle viscosity of $2 \times 10^{21} \mathrm{~Pa} \mathrm{~s}$, and a large lithospheric thickness of $120 \mathrm{~km}$. The resulting posterior viscosity models for ice model ICE-3G are remarkably different from the model in Figure 2a. The inversion, performed for two different a priori models (Figures $3 \mathrm{c}$ and $3 \mathrm{~d}$ ), favors the almost uniform viscosity model from Tushingham and Peltier [1991] in the mantle, and the larger viscosities in the uppermost mantle indicate the tendency to restore the original, $120 \mathrm{~km}$ thick elastic lithosphere. We conclude that the ice model information entering the inversion is crucial for the result, and hence the ice model should be based as much as possible on independent information such as geomorphological evidence (e.g., glacial moraines and erratic boulders) and glaciological model constraints.

\subsubsection{Present-Day Melting}

[27] The effect of uncertainties in knowledge of the present-day melting contribution of Antarctica is even more uncertain than the uncertainties arising from the models for the Late Pleistocene ice sheet distributions. Hence, we investigate the effect of different Antarctic melting scenarios on the inversion. In Figure $4 \mathrm{a}$, the ice model only comprises the Pleistocene ice sheets taken from model RSES, while in Figures $4 \mathrm{~b}-4 \mathrm{~d}$, the Antarctic melting scenarios $\mathrm{J} 92, \mathrm{~S} 1$, and $\mathrm{S} 2 \mathrm{M}$ from James and Ivins [1997] are included. All four resulting a posteriori viscosity profiles are, however, very similar. Differences are 

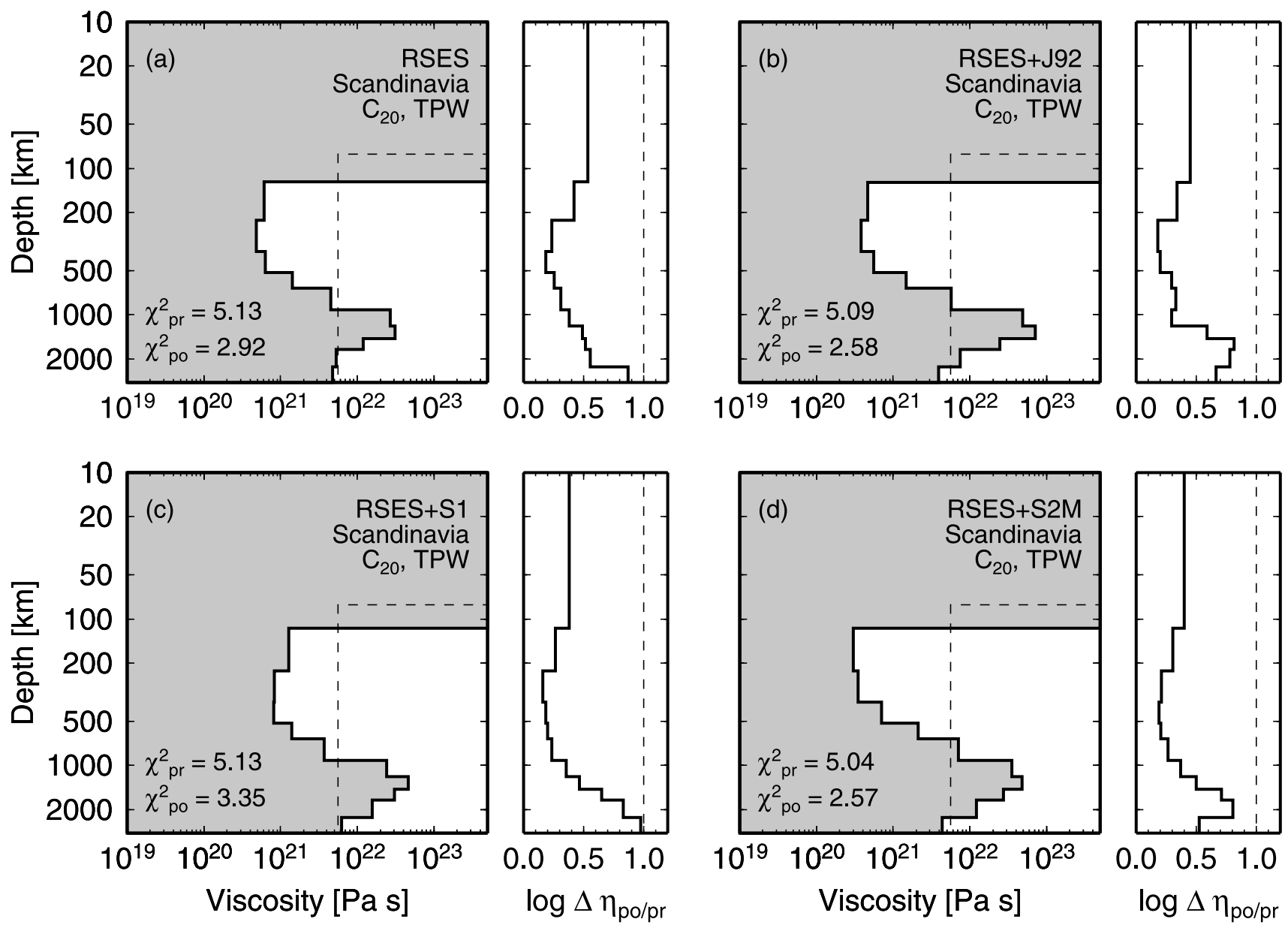

Figure 4. Four posterior viscosity models (thick lines) derived for different Antarctic present-day melting scenarios and a priori viscosity profiles (dashed lines). The data used are the Scandinavian sealevel data, $\dot{C}_{20}$, and $T P W$, and (a) no present-day melting, (b) J92 scenario, (c) S1 scenario, (d) S2M scenario. The smaller panels show the normalized posterior variances (solid lines).

present only in the lowermost mantle, but here the normalized posterior variances indicate a poor resolution for the inverse inference.

\subsection{Dependence on Observational Parameters}

[28] We next discuss viscosity profiles derived from different regional subsets of the observational database. All inversion results are performed for the four different a priori viscosity models discussed in section 5.1 to ensure that a reliable posterior model is found.

[29] In Figure 5a, the inverse inference is based on 569 RSL data from Scandinavia, $\dot{C}_{20}$, and $T P W$. We observe a significant reduction in the least squares misfit from an a priori value of $\chi_{p r}^{2}=5.09$ to an a posteriori value of $\chi_{p o}^{2}=$ 2.58 , with a reduction around $50 \%$. The a posteriori viscosity profile exhibits a large deviation from its a priori values. Viscosities in the upper mantle are monotonically increasing from around $2 \times 10^{20}$ to $10^{21} \mathrm{~Pa}$ s. No significant discrete jump in viscosity between the upper and lower mantle is necessary in the a posteriori profile, and viscosities in the lower mantle increase from $10^{21} \mathrm{~Pa} s$ below the $660-\mathrm{km}$ seismic discontinuity (660) to around $8 \times 10^{22} \mathrm{~Pa} \mathrm{~s}$ in $1000 \mathrm{~km}$ depth. Below that depth, viscosity is monotonically decreasing to values below $10^{22} \mathrm{~Pa}$ at the core-mantle boundary $(\mathrm{CMB})$. Lithospheric thickness has increased to $100 \mathrm{~km}$. The normalized posterior variances have dropped by more than $50 \%$ in the mantle down to $1500 \mathrm{~km}$ depth, and are still significantly reduced below that depth. Hence, the formal inverse procedure has been successful in improving the fit between model predictions and RSL observations, and a more detailed viscosity structure can be constrained on the basis of the data set.

[30] In Figure 5b, the 487 European RSL data (British Isles, German, Dutch, and French coasts) are used together with $\dot{C}_{20}$, and $T P W$. Again, the least squares misfit has improved from an a priori value of $\chi_{p r}^{2}=2.74$ to an a posteriori value of $\chi_{p o}^{2}=2.00$, an improvement of more than $30 \%$. The posterior viscosity model increases monotonically from values around $4 \times 10^{20} \mathrm{~Pa} \mathrm{~s}$ below the lithosphere to $3 \times 10^{22} \mathrm{Pas}$ in the central parts of the lower mantle. Note also the reduction in lithospheric thickness for the posterior model to $70 \mathrm{~km}$. As it can be seen in the normalized posterior variances, the apparent resolving power of the European RSL data is as good in the lowermost mantle, when compared to the Scandinavian RSL data.

[31] In a next step, we use both the Scandinavian and the European RSL data (1056 RSL data), together with $\dot{C}_{20}$ and $T P W$, extending the regional cover of RSL data to the 

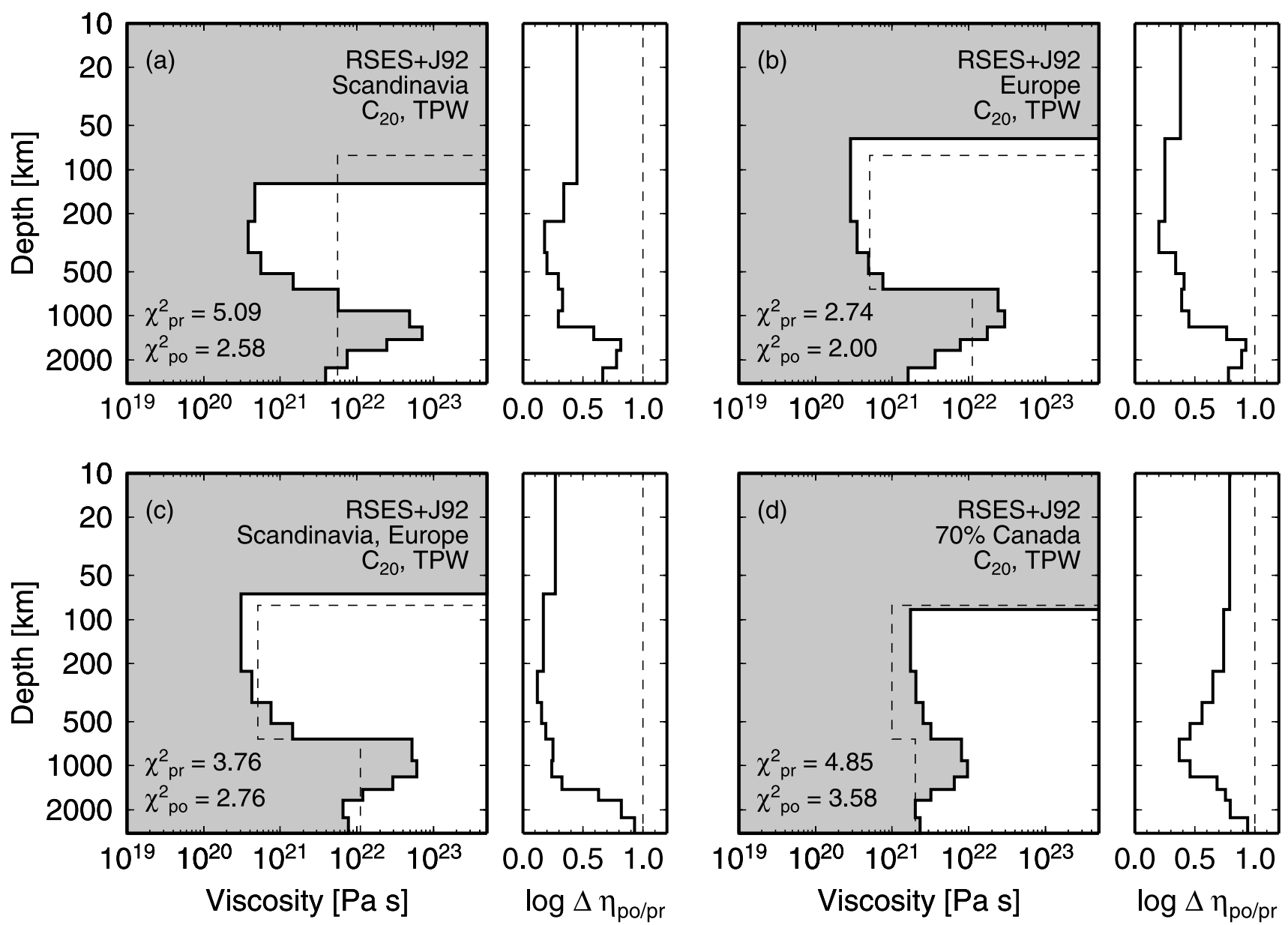

Figure 5. Four posterior viscosity models derived for different data subsets. (a) Scandinavian sea-level data, $\dot{C}_{20}$, and $T P W$, (b) British Isles sea-level data, $\dot{C}_{20}$, and $T P W$, (c) Scandinavian and British Isles sealevel data, $\dot{C}_{20}$, and $T P W$, (d) Canadian sea-level data, $\dot{C}_{20}$, and $T P W$.

southwest. The resulting posterior viscosity model shown in Figure $5 \mathrm{c}$ is very similar to the previously discussed ones. Again, the inversion has reduced the lithospheric thickness to around $70 \mathrm{~km}$. The improvement in least squares misfit from $\chi^{2} p r=3.76$ to $\chi_{p o}^{2}=2.76$ is around $30 \%$, and the normalized posterior variances indicate apparent resolving power throughout most of the mantle region.

[32] A different picture emerges when we use the 58 Canadian RSL data, together with the $\dot{C}_{20}$ and TPW observations. The a posteriori viscosity model shown in Figure $5 \mathrm{~d}$ reveals a high viscosity upper mantle of almost uniform viscosity around $2 \times 10^{21} \mathrm{~Pa} \mathrm{~s}$, and a lower mantle viscosity close to $10^{22} \mathrm{~Pa} \mathrm{~s}$ down to $1000 \mathrm{~km}$ depth and decreasing to values lower than $10^{22} \mathrm{~Pa}$ s below [see also Nakada and Lambeck, 1991; Ivins and Sammis, 1995]. The stiffer upper mantle can possibly be related to the older, cratonic origin of the Canadian Shield. However, we have to stress that the Canadian ice model used has not yet been improved on the basis of new field data such as glacigenic sediments and Late Pleistocene and Holocene coastline data in the way as it has been done with the Weichselian and British ice sheet complexes.

[33] In the next two examples, we have used present-day observables from Scandinavia to infer a viscosity model through the formal inversion of the data. The first data set taken from Ekman [1998] is the present-day uplift rate related to the disintegration of the Weichselian ice sheet. The data are derived from sea level records, lake-level records, and repeated high-precision levelings, and they reveal an uplift signal closely correlated to the former ice sheet. As the uplift signal samples a period of around 100 years, the measured uplift rate is biased by the eustatic sea level rise during that time period. While Ekman [1998] has corrected his data by a sea level rise of $1.2 \mathrm{~mm} \mathrm{yr}^{-1}$ taken from Nakiboglu and Lambeck [1991], a simple search for a best model fit with the eustatic sea level contribution as free parameter reveals a value of $2.2 \mathrm{~mm} \mathrm{yr}^{-1}$ to obtain a minimum misfit for fitting the uplift rate data. This value is above the upper bound of the recent estimate in the IPCC report [Church et al., 2001] of $(1.5 \pm 0.5) \mathrm{mm} \mathrm{yr}^{-1}$, but it is in accordance with more recent uplift rates derived from the BIFROST GPS campaign [Scherneck et al., 1998, 2001]. We note, however, that a lower value for the predicted eustatic contribution can be achieved by using the a posteriori viscosity profile for the RSL data (Figure 5a).

[34] As indicated by the posterior variances in Figure 6a, the sensitivity of the uplift rate data set is restricted to the 

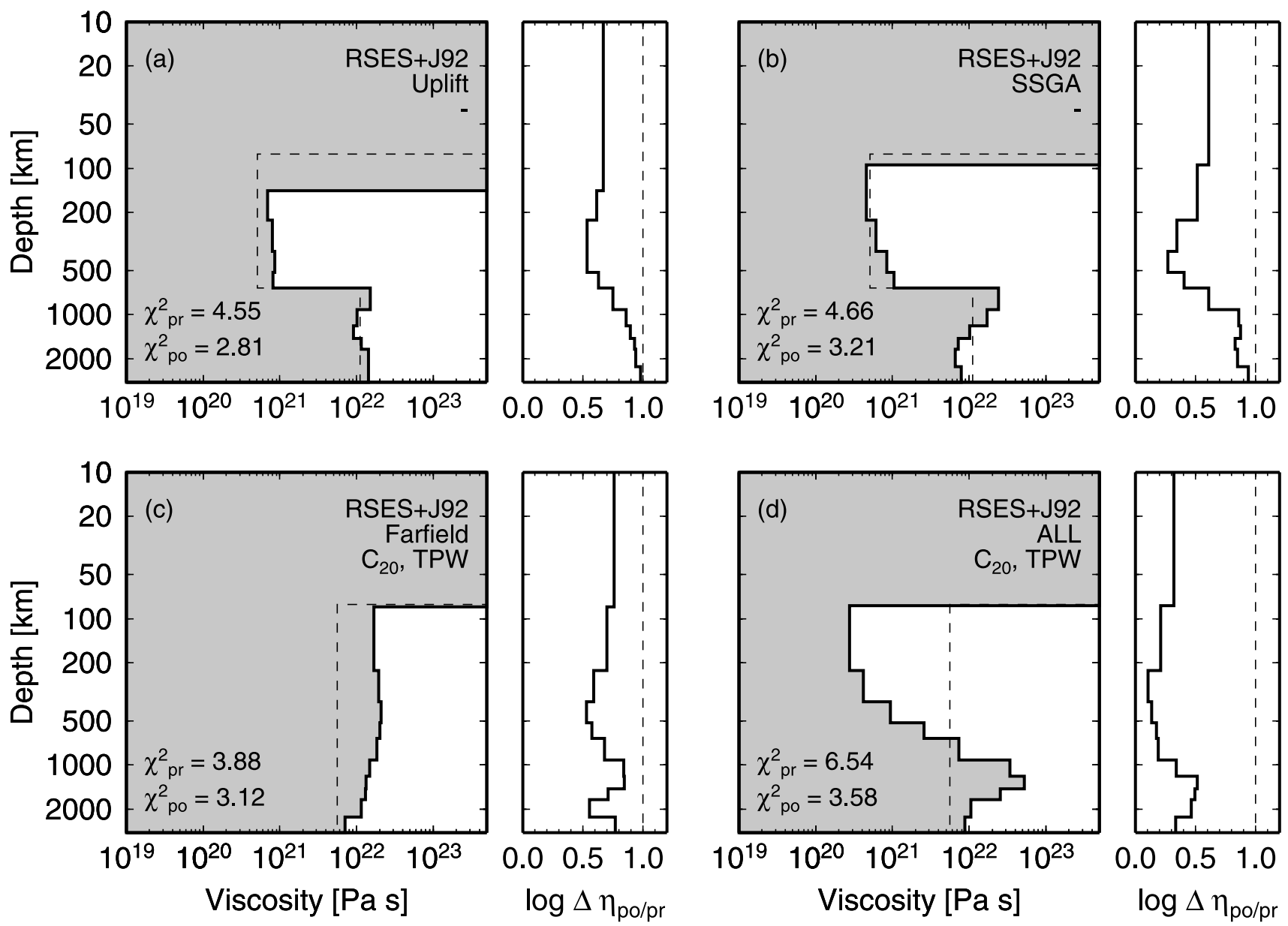

Figure 6. Four posterior viscosity models derived for different data subsets. (a) Far-field sea-level data, $\dot{C}_{20}$, and $T P W,($ b) solid-surface gravity anomaly data from Ekman [1998], (c) uplift rate data from Ekman [1998], (d) all available data.

upper $1000 \mathrm{~km}$ of the mantle. Viscosities increase slightly from $5 \times 10^{20}$ to $10^{21} \mathrm{~Pa} \mathrm{~s}$ within the upper mantle, and jump to values around $10^{22} \mathrm{~Pa} \mathrm{~s}$ in the lower mantle. Lithospheric thickness has increased to around $110 \mathrm{~km}$. Again, the jump across the $660-\mathrm{km}$ discontinuity depends on the a priori viscosity profile used. The least squares misfit is reduced by about $30 \%$ as a result of the inversion.

[35] The solid-surface gravity anomaly observations from Ekman [1998] for the Scandinavian Peninsula are derived from the uplift rate data and are scaled by data from a profile of repeated gravity measurements [Ekman and Mäkinen, 1996]. The posterior viscosity model based on this second data set shown in Figure $6 \mathrm{~b}$ has a similar depth sensitivity range as the result for the uplift data. The posterior viscosity model is very similar to the previous inference. It is important to note that the posterior viscosity models based on the present-day observational data discussed above are similar to the inferences from the Late Pleistocene and Holocene relative sea level data.

[36] In Figure 6c, the far-field RSL data are used to infer a viscosity model from the inversion. While we are able to reduce the least squares misfit from a priori values of $\chi_{p r}^{2}=$ 3.88 to an posterior value of $\chi_{p o}^{2}=3.12$, reducing the misfit by $20 \%$, we obtain a viscosity model with a rather stiff mantle. Viscosities are around $10^{22} \mathrm{~Pa} \mathrm{~s}$ in the mantle, and lithospheric thickness has been maintained around $80 \mathrm{~km}$. However, the normalized posterior variances are less satisfactorily reduced than in the previous examples.

[37] In a final inversion, we have combined all RSL data, the uplift data from Scandinavia, and $\dot{C}_{20}$ and $T P W$ to estimate a global posterior viscosity model. The result is shown in Figure 6d. The global posterior viscosity model still has the same characteristics as the results for subsets of the observations discussed above; a monotonic increase of viscosity in the upper mantle from $4 \times 10^{20}$ to $10^{22} \mathrm{~Pa} \mathrm{~s}$, no large jump of viscosity across the 660 discontinuity, and peak values around $10^{23} \mathrm{~Pa} \mathrm{~s}$ in around $1000 \mathrm{~km}$ depth. Below, viscosity decreases again to values around $10^{22} \mathrm{~Pa} \mathrm{~s}$. However, we are only able to reduce the least squares misfit to $\chi_{p o}^{2}=3.58$.

[38] This poorer improvement indicates that regional solutions for the viscosity model should be favored over a single global solution. Lateral variations in mantle viscosity for different regions (Scandinavia close to the Mid-Atlantic ridge system, with properties laterally varying toward the Baltic Shield; Canada located on an old craton; the far-field data mostly from oceanic areas) can be significant enough to influence the model response [e.g., Kaufmann and $W u$, 1998; Kaufmann et al., 2000]. However, as stated in the 

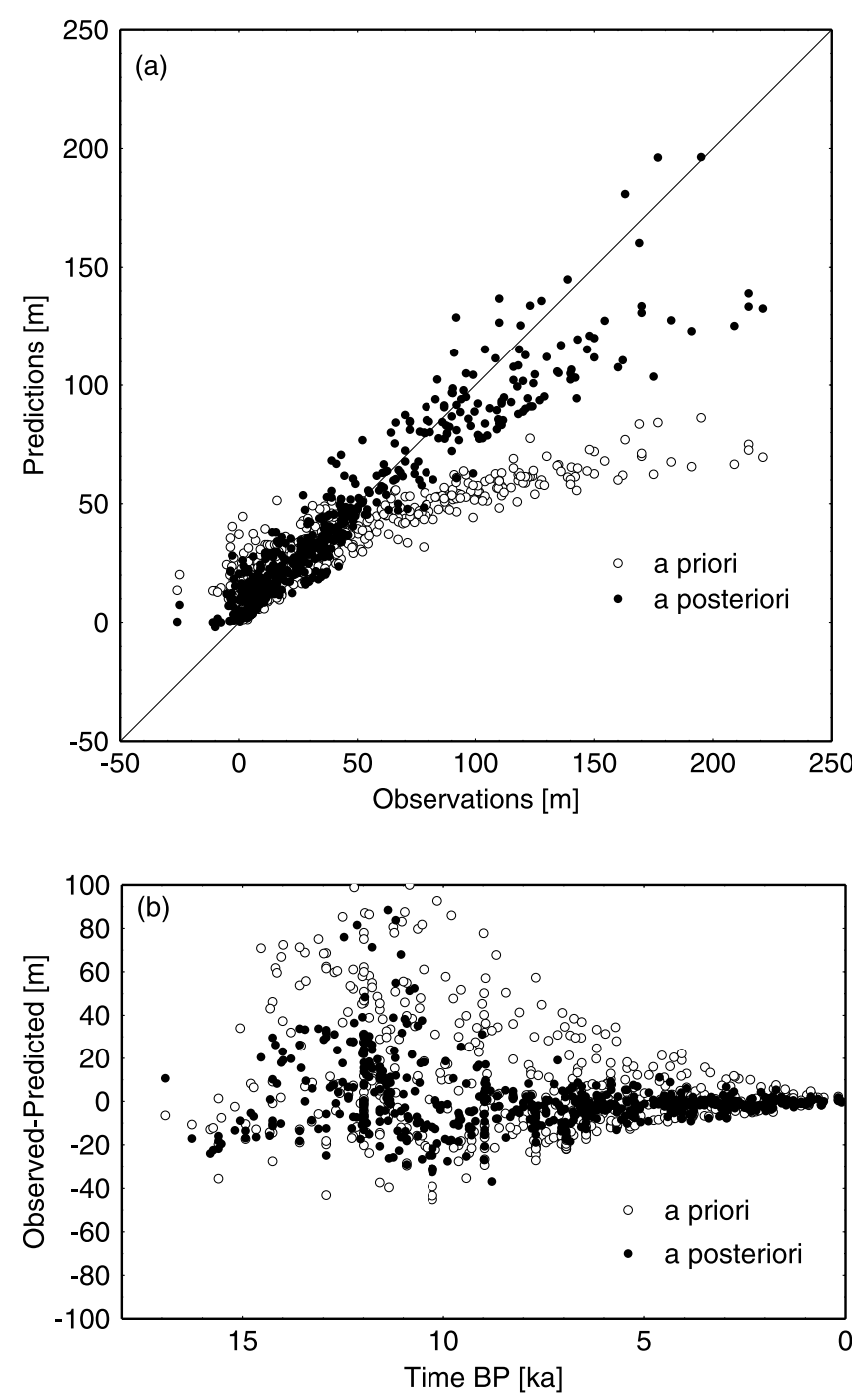

Figure 7. Comparison of relative sea-level observations and predictions, based on the reference run. (a) Predicted versus observed relative sea-level data. (b) Difference of observed minus predicted relative sea-level data versus time before present.

introduction, we need improved ice models to estimate lateral variations in mantle properties correctly.

\subsection{Comparison of RSL Predictions and Observations}

[39] We continue discussing a regional solution for Fennoscandia, based on the Scandinavian RSL data and the $\dot{C}_{20}$ and $T P W$ observations (Figure 5a). For this reference model, we compare the RSL observations with model predictions for the a priori and the a posteriori viscosity profiles. In Figure $7 \mathrm{a}$, observations are plotted versus predictions, a relationship which should be linear, if all predictions match the corresponding observations. We observe some substantial discrepancies from the linear relationship, but in general the predictions agree well with the observations. For the a priori profile, the correlation is 0.88 and the slope of the data set is 0.62 . For the a posteriori profile, the correlation is 0.96 and the slope is 0.95 . Hence, the inversion has improved the data fit to a slope, which is almost unity. In
Figure $7 \mathrm{~b}$, the residual differences (observed minus predicted relative sea level) are shown as a function of time. Here, it is evident that the older coastlines are less well predicted, with considerable scatter before 7000 years. However, most of the scatter can be explained by either inadequacies in the regional ice model, or anomalous data from the field (see Lambeck et al. [1998a] for a more detailed discussion of the data inconsistencies). As before, the inversion has been able to reduce the scatter for older coastlines.

\subsection{Comparison of Uplift and Gravity Predictions and Observations}

[40] We now compare present-day predictions of uplift and gravity rates to the observations for the reference model. In Figure 8a, the observed radial uplift velocities from Ekman [1998] are redrawn. These data are corrected with an eustatic sea level contribution of $1.2 \mathrm{~mm} \mathrm{yr}^{-1}$ as quoted by Ekman [1998]. We observe an elliptical region of positive uplift velocities, from 3 to $4 \mathrm{~mm} \mathrm{yr}^{-1}$ around the Scandinavian coastline and increasing to almost $10 \mathrm{~mm}$ $\mathrm{yr}^{-1}$ over Bothnian Bay, the center of the former ice sheet over Scandinavia. The uplift pattern is almost symmetrical and coincides well with the ice model for that region. In Figure $8 b$, model predictions of the radial uplift velocities for the posterior reference model are shown. In general, the elliptical uplift pattern is well reproduced, with uplift velocities increasing from $2 \mathrm{~mm} \mathrm{yr}^{-1}$ over Denmark to $10 \mathrm{~mm} \mathrm{yr}^{-1}$ in the Bothnian Bay region. The reduction in least squares misfit from an a priori value of 6.02 to an a posteriori value of 2.70 indicates that the formal inversion has been successful in improving the fit of the predictions to the data set.

[41] Similar conclusions can be drawn from the fit to the solid-surface gravity anomaly observations. Here, the observations taken from Ekman [1998] are redrawn in Figure 9a, with values of $0.2 \mu \mathrm{Gal} \mathrm{yr}^{-1}$ over Denmark increasing to $2 \mu \mathrm{Gal} \mathrm{\textrm {yr } ^ { - 1 }}$ over the Bothnian Bay. The observations closely match the former ice sheet distribution, indicating that a glacial origin of the remaining disequilibrium is likely. The model predictions for the posterior reference model in Figure $9 \mathrm{~b}$ are again closely resembling the observations. As in the uplift prediction, the inversion has been able to reduce the least squares misfit significantly.

\section{Discussion}

[42] In this final section, we discuss our best fitting inference of the viscosity profile in view of some previously published results for mantle viscosity estimates from the literature. We start comparing our best fitting profile with an earlier inference from Kaufmann and Lambeck [2000], based on the simultaneous inversion of geoid and rebound observations. Therefore, in Figure 10a two mantle viscosity profiles are redrawn, our best fitting result from this study and profile B from Kaufmann and Lambeck [2000]. In general, we observe a good agreement of the resulting viscosity profiles. Both are characterized by an increase of viscosity in the upper mantle, a viscosity peak in $1000 \mathrm{~km}$ depth, and values around $10^{22} \mathrm{~Pa}$ s below that depth. The upper mantle viscosity resulting from the simultaneous inversion, however, is slightly lower than the one for the 
Radial velocity $[\mathrm{mm} / \mathrm{yr}]$
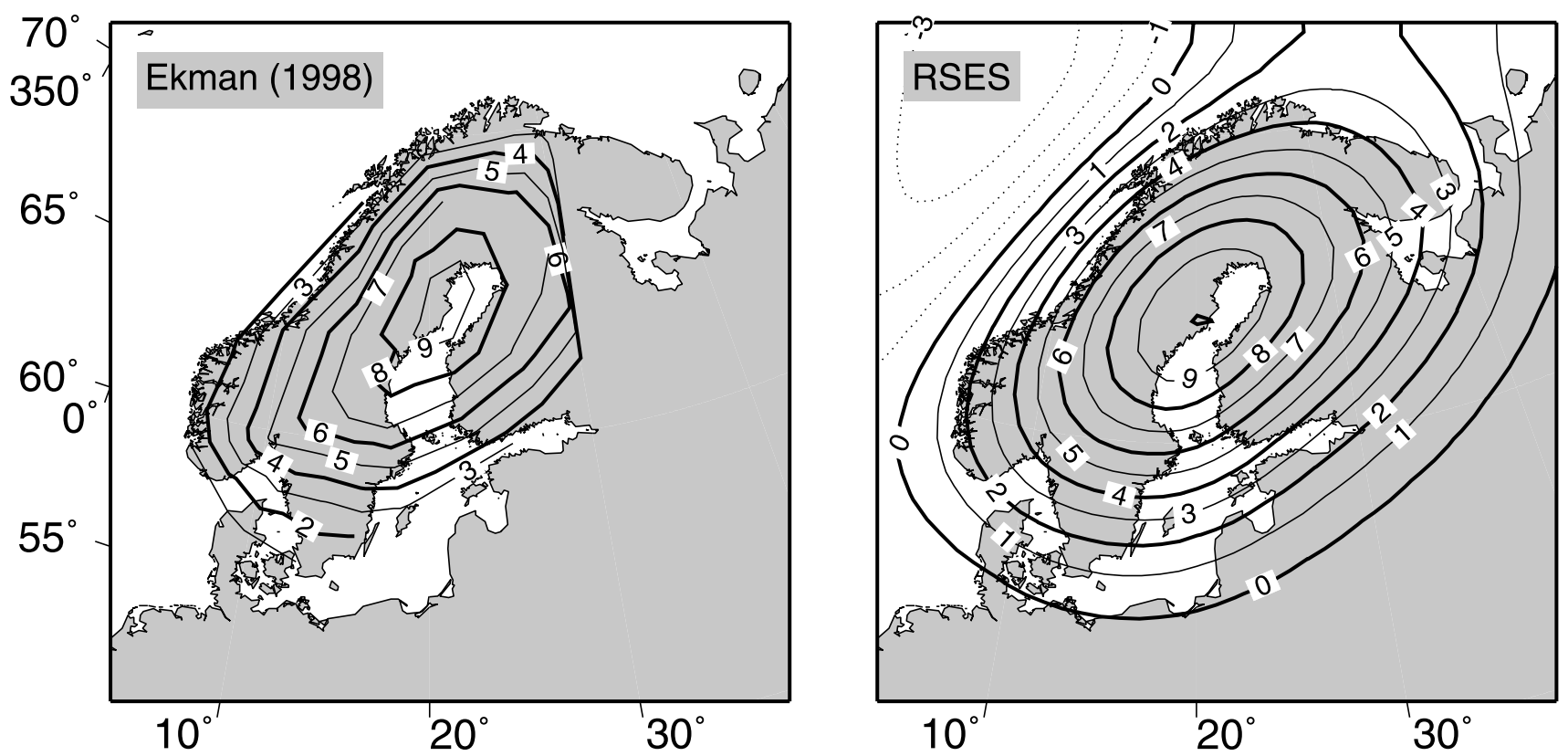

Figure 8. (a) Observed [from Ekman, 1998] and (b) predicted radial velocity pattern for Fennoscandia.

present result. Hence, we can satisfactorily predict the largescale geoid anomaly induced by mantle flow and the glacially induced observables such as relative sea levels and variable rotation induced by the ice-age mass transfer. As these two processes, mantle convection and glacial isostatic adjustment, have vastly different timescales $\left(10^{7}\right.$ years versus $10^{4}-10^{5}$ years), we conclude that the rheological behavior of the Earth's mantle is similar on both timescales [Forte and Mitrovica, 1996; Mitrovica and Forte, 1997]

[43] Next, we compare our best fitting viscosity profile with models from other studies. In Figure $10 \mathrm{~b}$, two inferences from Lambeck et al. [1996, 1998a] based on the interpretation of Late Pleistocene and Holocene strandlines in the British Isles and Fennoscandian regions, are compared to our newly derived profile. The five-layer viscosity

\section{Secular change in solid-surface gravity anomaly [ $\mu \mathrm{Gal} / \mathrm{yr}]$}
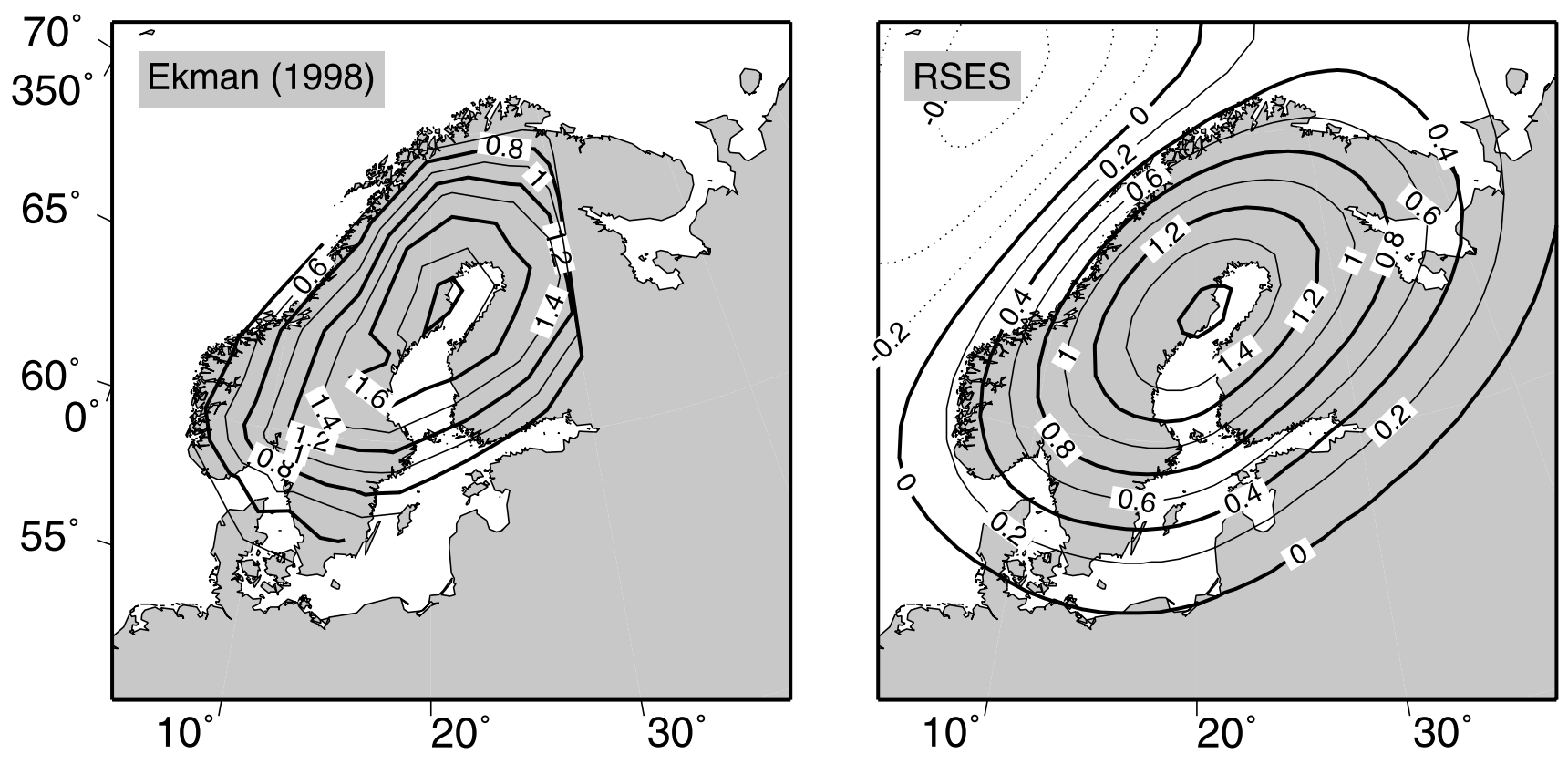

Figure 9. (a) Observed [from Ekman, 1998] and (b) predicted secular change in solid-surface gravity pattern for Fennoscandia. 


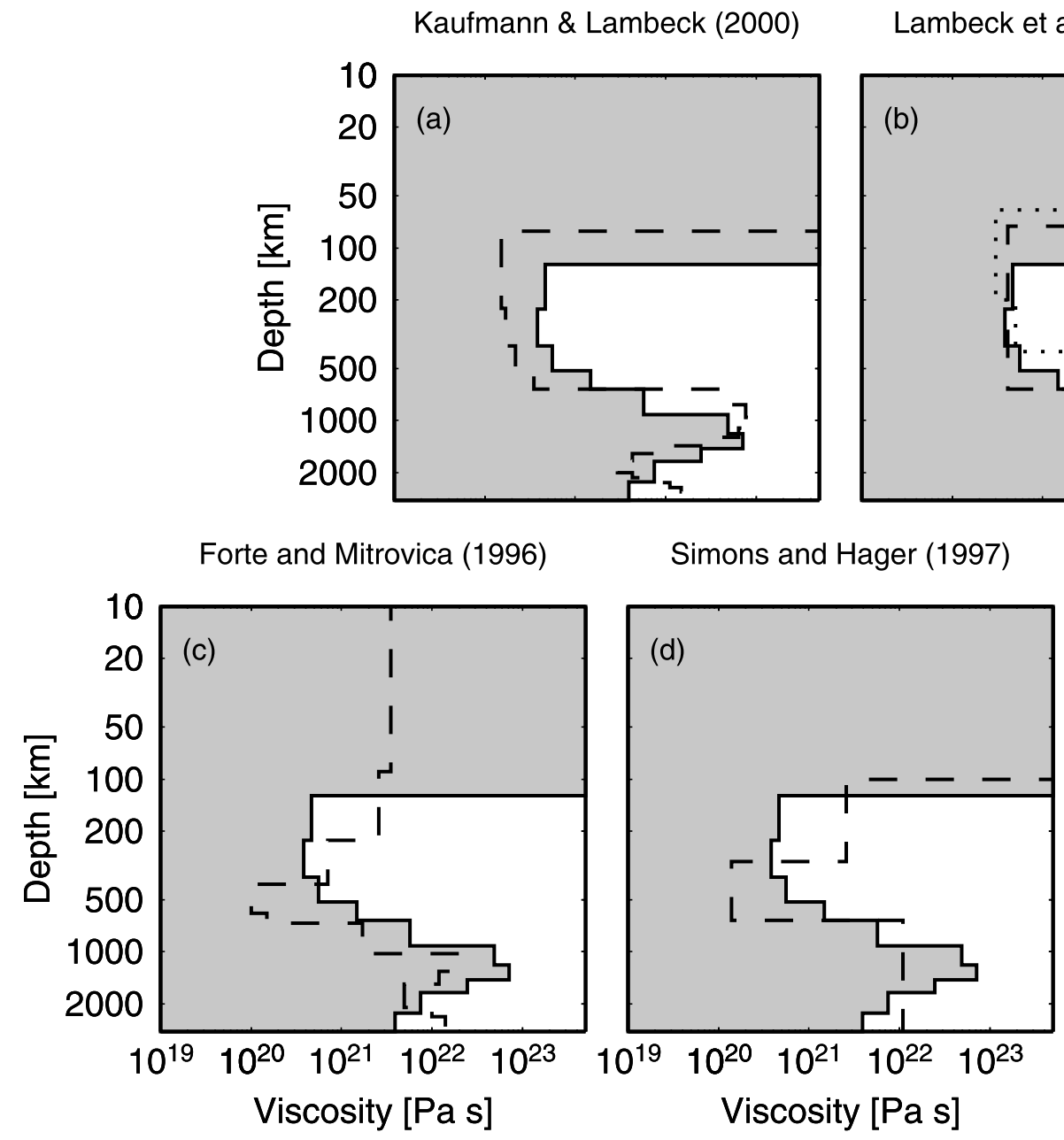

Lambeck et al. $(1996,1998)$
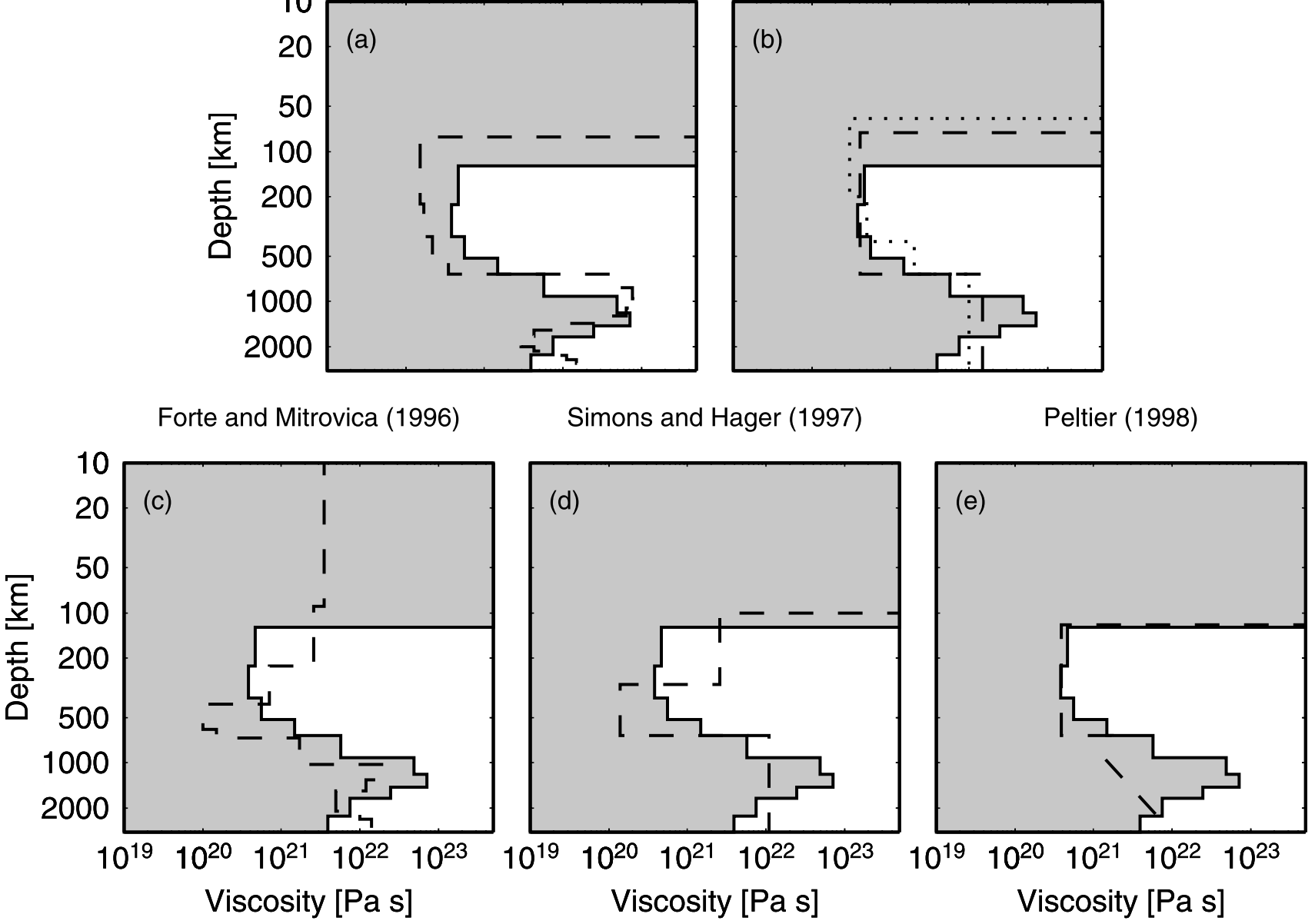

Figure 10. Comparison of mantle viscosity profiles. This study (solid lines), and (a) profile B from Kaufmann and Lambeck [2000] (dashed line), (b) Lambeck et al. [1996] (dotted line), Lambeck et al. [1998a] (dashed line) (c) Forte and Mitrovica [1996] (dashed line), (d) Simons and Hager [1997] (dashed line), (e) Peltier [1998a] (dashed line).

model based on the RSL data from the British Isles and a high-resolution ice model for that region achieves an excellent agreement with our new model in the upper mantle. The three-layer viscosity profile derived from the Scandinavian rebound data represents a good approximation of the average upper mantle viscosity for our best fitting model. In the lower mantle, both models slightly underestimate the volume-averaged viscosity of our newly derived viscosity profile, which might be a consequence of the poorer resolution of the Lambeck et al. [1996, 1998a] models in this depth.

[44] In Figure 10c, we compare the Forte and Mitrovica [1996] inference, which is based on the simultaneous inversion of the large-scale geoid anomaly and postglacial decay times, to our result. While we find an agreement in the lowermost mantle, the Forte and Mitrovica [1996] viscosity model yields consistently lower values in the transition zone and the uppermost lower mantle. However, we explain this discrepancy with the different ice model ICE-3G used for the inversion. This in fact can be seen, when we compare the Forte and Mitrovica [1996] inference from Figure 10c with our a posteriori prediction based on the ICE-3G ice model in Figure 3d. Here, both viscosity profiles are very similar. We conclude that the choice of the ice model still determines the outcome of the inversion.

[45] Next, comparing the viscosity estimate from Simons and Hager [1997] to our inference as in Figure 10d reveals a discrepancy in the upper mantle, which, however, can probably be attributed to the use of ICE-3G again.

[46] Finally, in Figure 10e a comparison is performed between the inverse inference from Peltier [1998a] (a simplified version of the VM3 model is redrawn) and our best fitting viscosity profile. Again, the lower mantle viscosity estimates agree well, but in the uppermost lower mantle and the VM3 inference results in significantly lower viscosities than our new estimate. As the Peltier [1998a] inference uses the ICE-5 ice model, a derivative of the ICE$3 \mathrm{G}$ model, the differences are likely to result from ice model differences again.

\section{Conclusions}

[47] In this paper we have presented results for a formal inversion of several observational data related to the glacial isostatic adjustment process of the Earth with respect to mantle viscosity. Our results for the inversion consistently 
improve the a priori fit of the model predictions to the data, both in terms of reduced least squares misfit and a reduction in normalized posterior variances. The mantle viscosity profiles inferred are robust against model parameter assumptions such as the a priori viscosity model and the model discretization. However, the choice of the global ice model used as prescribed input model remains crucial for the results obtained. Lateral variations in mantle properties need to be addressed by either discussing regional mantle viscosity models or, in the future, by directly incorporating the lateral viscosity variations into the model.

[48] Our mantle viscosity profiles are characterized by a two order of magnitude variation with depth. Upper mantle viscosity varies with depth between $2 \times 10^{20}$ and $10 \times 10^{20}$ $\mathrm{Pa} \mathrm{s}$, with a volume-averaged value of $7 \times 10^{20} \mathrm{~Pa} \mathrm{~s}$, generally increasing toward the $660-\mathrm{km}$ seismic discontinuity. However, the rebound-related observations cannot distinguish between a sharp increase of viscosity between the upper and lower mantle, or a more gradual variation. Viscosity in the lower mantle is generally above $10^{22} \mathrm{~Pa} \mathrm{~s}$, with peak values closer to $10^{23} \mathrm{~Pa}$ around $1000 \mathrm{~km}$ depth. The volume-averaged value in the lower mantle is $2 \times 10^{22}$ $\mathrm{Pa}$ s. In the bottommost part of the mantle, viscosity decreases again, but here the resolution of the observations used becomes inferior. The inferred viscosity profile is also able to explain the large-scale geoid anomaly related to mantle flow processes.

[49] Acknowledgments. We would like to thank Thomas James for providing the present-day Antarctic mass balance scenario. The figures in this paper are drawn using the GMT graphics package (see Wessel and Smith [1991] for details). Two anonymous referees have greatly helped to improve the original manuscript.

\section{References}

Čadek, O., and L. Fleitout, A global geoid model with imposed plate velocities and partial layering, J. Geophys. Res., 104, 29,055-29,075, 1999.

Chappell, J., and N. J. Shackleton, Oxygen isotopes and sealevel, Nature, 324, 137-140, 1986.

Church, J. A., J. M. Gregor, P. Huybrechts, M. Kuhn, K. Lambeck, M. T. Nhuan, D. Qin, and P. L. Woodworth, Changes in Sea Level, Chapter 11, Intergovernmental Panel on Climate Change, Third Assessment Report, Cambridge Univ. Press, New York, 2001.

Dziewonski, A. M., and D. L. Anderson, Preliminary reference Earth model, Phys. Earth Planet. Int., 25, 279-356, 1981.

Ekman, M., Recent postglacial rebound of Fennoscandia: A short review and some numerical results, in Dynamics of the Ice Age Earth: A Modern Perspective, edited by P. Wu, pp. 383-392, Trans Tech, Clausthal-Zellerfield, Germany, 1998.

Ekman, M., and J. Mäkinen, Recent postglacial rebound, gravity change and mantle flow in Fennoscandia, Geophys. J. Int., 126, 229-234, 1996.

Farrell, W. E., and J. A. Clark, On postglacial sea level, Geophys. J. R. Astron. Soc., 46, 647-667, 1976.

Forte, A. M., and J. X. Mitrovica, New inferences of mantle viscosity from joint inversion of long-wavelength mantle convection and post-glacial rebound data, Geophys. Res. Lett., 23(10), 1147-1150, 1996.

Gornitz, V., S. Lebedeff, and J. Hansen, Global sea level trend in the past century, Science, 215, 1611-1614, 1982.

Han, D., and J. Wahr, The viscoelastic relaxation of a realistically stratified Earth, and a further analysis of postglacial rebound, Geophys. J. Int., 120, 287-311, 1995.

Ivins, E. R., and C. G. Sammis, On lateral viscosity contrast in the mantle and the rheology of low frequency geodynamics, Geophys. J. Int., 123, 305-322, 1995.

James, T. S., and E. R. Ivins, Global geodetic signatures of the Antarctic ice sheet, J. Geophys. Res., 102, 605-633, 1997.

Johnston, P., and K. Lambeck, Postglacial rebound and sea level contributions to changes in the geoid and the Earth's rotation axis, Geophys. J. Int., 136, 537-558, 1999.

Kaufmann, G., and K. Lambeck, Mantle dynamics, postglacial rebound and the radial viscosity profile, Phys. Earth Planet. Inter, 121, 303-327, 2000.

Kaufmann, G., and P. Wu, Lateral asthenospheric viscosity variations and postglacial rebound: A case study for the Barents Sea, Geophys. Res. Lett., 25(11), 1963-1966, 1998.

Kaufmann, G., P. Wu, and G. Li, Glacial isostatic adjustment in Fennoscandia for a laterally heterogeneous Earth, Geophys. J. Int., 143, 262273, 2000.

Lambeck, K., Changes in length-of-day and atmospheric circulation, Nature, 286, 104-105, 1980.

Lambeck, K., Glacial rebound of the British Isles, 2, A high-resolution, high-precision model, Geophys. J. Int., 115, 960-990, 1993.

Lambeck, K., and J. Chappell, Sea level change through the last glacial cycle, Science, 292, 679-686, 2001.

Lambeck, K., P. Johnston, C. Smither, and M. Nakada, Glacial rebound of the British Isles, 3, Constraints on mantle viscosity, Geophys. J. Int., 125, 340-354, 1996.

Lambeck, K., C. Smither, and P. Johnston, Sea-level change, glacial rebound and mantle viscosity for northern Europe, Geophys. J. Int., 134, $102-144,1998 \mathrm{a}$.

Lambeck, K., C. Smither, and M. Ekman, Tests of glacial rebound models for Fennoscandia based on instrumented sea- and lake-level records, Geophys. J. Int., 135, 375-387, 1998b.

Lambeck, K., Y. Yokoyama, and T. Purcell, Into and out of the Last Glacial Maximum: Sea-level change during Oxygen Isotope Stages 3 and 2, Quat. Sci. Rev., 21, 343-360, 2002.

$\mathrm{Li}$, X. D., and B. Romanowicz, Global mantle shear velocity model developed using nonlinear asymptotic coupling theory, J. Geophys. Res., 101, 22,245-22,272, 1996.

Love, A. E. H., Some Problems of Geodynamics, Cambridge Univ. Press, New York, 1911.

McCarthy, D. D., and B. J. Luzum, Path of the mean rotation pole from 1899 to 1994, Geophys. J. Int., 125, 623-629, 1996.

Milne, G. A., and J. X. Mitrovica, Postglacial sea-level change on a rotating Earth, Geophys. J. Int., 133, 1-19, 1998.

Mitrovica, J. X., Haskell [1935] revisited, J. Geophys. Res., 101, 555-569, 1996.

Mitrovica, J. X., and A. M. Forte, Radial profile of mantle viscosity: Results from a joint inversion of convection and postglacial rebound observables, J. Geophys. Res., 102, 2751-2769, 1997.

Mitrovica, J. X., and G. A. Milne, Glaciation-induced perturbations in the earth's rotation: A new appraisal, J. Geophys. Res., 103, 985-1005, 1998.

Mitrovica, J. X., and W. R. Peltier, Pleistocene deglaciation and the global gravity field, J. Geophys. Res., 94, 13,651-13,671, 1989.

Mitrovica, J. X., and W. R. Peltier, A complete formalism for the inversion of post-glacial rebound data: Resolving power analysis, Geophys. J. Int., 104, 267-288, 1991

Mitrovica, J. X., and W. R. Peltier, A comparison of methods for the inversion of viscoelastic relaxation spectra, Geophys. J. Int., 108, 410414, 1992.

Mitrovica, J. X., J. L. Davis, and I. I. Shapiro, A spectral formalism for computing three-dimensional deformations due to surface loads, 1 , Theory, J. Geophys. Res., 99, 7057-7073, 1994.

Munk, W. H., and G. J. F. MacDonald, The Rotation of the Earth: A Geophysical Discussion, Cambridge Univ. Press, New York, 1960.

Nakada, M., and K. Lambeck, Glacial rebound and relative sea-level variations: A new appraisal, Geophys. J. R. Astron. Soc., 90, 171-224, 1987.

Nakada, M., and K. Lambeck, The melting history of the late Pleistocene Antarctic ice sheet, Nature, 333, 36-40, 1988.

Nakada, M., and K. Lambeck, Late Pleistocene and Holocene sealevel change; evidence for lateral mantle viscosity structure?, in Glacial Isostasy, Sea-Level and Mantle Rheology, edited by R. Sabadini, K. Lambeck, and E. Boschi, pp. 79-94, Kluwer Acad., Norwell, Mass., 1991.

Nakiboglu, S. M., and K. Lambeck, Secular sea-level change, in Glacial Isostasy, Sea-Level and Mantle Rheology, edited by R. Sabadini, K. Lambeck, and E. Boschi, pp. 237-258, Kluwer Acad., Norwell, Mass., 1991.

Nerem, R. S., and S. M. Klosko, Secular variations of the zonal harmonics and polar motion as geophysical constraints, in Global Gravity Field and Its Temporal Variations, edited by R. H. Rapp, A. A. Cazenave, and R. S. Nerem, pp. 152-163, Springer-Verlag, New York, 1996.

Peltier, W. R., The inverse problem for mantle viscosity, Inverse Probl., 14(3), 441-478, 1998a.

Peltier, W. R., Postglacial variations in the level of the sea: Implications for climate dynamics and solid-earth geophysics, Rev. Geophys., 36(4), $603-$ 689,1998 b.

Peltier, W. R., and J. T. Andrews, Glacial-isostatic adjustment, 1, The forward problem, Geophys. J. R. Astron. Soc., 46, 605-646, 1976. 
Romanowicz, B., Attenuation tomography of the Earth's mantle: A review of current status, Pure Appl. Geophys., 153, 257-272, 1998.

Scherneck, H.-G., J. M. Johansson, J. X. Mitrovica, and J. L. Davis, The BIFROST project: GPS determined 3-D displacement rates in Fennoscandia from 800 days of continuous observations in the SWEPOS network, Tectonophysics, 294, 305-321, 1998.

Scherneck, H.-G., J. M. Johansson, M. Vermeer, J. L. Davis, G. A. Milne, and J. X. Mitrovica, BIFROST Project: 3D-crustal deformation rates derived from GPS confirm postglacial rebound in Fennoscandia, Earth Planets Space, 53(7), 703-708, 2001.

Simons, M., and B. H. Hager, Localization of the gravity field and the signature of glacial rebound, Nature, 390, 500-504, 1997.

Snieder, R., The role of nonlinearity in inverse problems, Inverse Probl., 14(3), 387-404, 1998.

Su, W., and A. M. Dziewonski, Predominance of long-wavelength heterogeneity in the mantle, Nature, 352, 121-126, 1991

Tarantola, A., and B. Valette, Generalized nonlinear inverse problems solved using the least squares criterion, Rev. Geophys. Space Phys., 20(2), 219-232, 1982.

Tushingham, A. M., and W. R. Peltier, Ice-3G: A new global model of late Pleistocene deglaciation based upon geophysical predictions of postglacial relative sea level change, J. Geophys. Res., 96, 4497-4523, 1991. Wessel, P., and W. H. F. Smith, Free software helps map and display data, Eos Trans. $A G U, 72,441-446,1991$.

Wieczerkowski, K., J. X. Mitrovica, and D. Wolf, A revised relaxation-time spectrum for Fennoscandia, Geophys. J. Int., 139, 69-86, 1999.

G. Kaufmann, Institut für Geophysik, Universität Göttingen, Herzberger Landstrasse 180, 37075 Göttingen, Germany. (gkaufman@unigeophys.gwdg.de)

K. Lambeck, Research School of Earth Sciences, Australian National University, Canberra, ACT 0200, Australia. (kurt.lambeck@anu.edu.au) 